Research Article

\title{
A biomechanical comparison of midshaft clavicle plate fixation between two screws and three screws on each side of the fractures
}

\author{
Naufal Ranadi Firas ${ }^{1 *}$, Erwin Ramawan ${ }^{2}$ \\ 1,2) Department of Orthopaedic and Traumatology, Faculty of Medicine Universitas Airlangga- Dr.Soetomo General Hospital, \\ Surabayaa
}

\section{AR T I C L E I N F O \\ Submitted : $9^{\text {th }}$ March 2021 \\ Accepted : $2^{\text {nd }}$ August 2021 \\ Published : 25 $5^{\text {th }}$ January 2022}

\section{Keywords:}

biomechanics, clavicle fracture, plate, screw

\section{*Correspondence:}

nau.orthobaya@gmail.com

This is an Open acces article under the CC-BY license

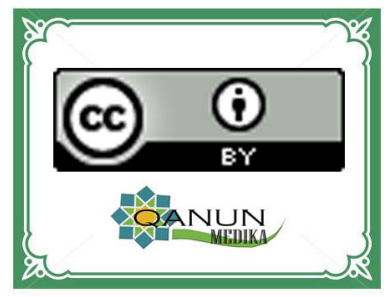

\begin{abstract}
The operative management of mid-clavicle fractures with plate and screw fixation is often performed, with either two or three screws on each side of the fracture. This research aimed to compare biomechanical stability on plate and screw fixation of the middle clavicle fracture with two screws and three screws on each fracture side. There were 12 samples of the fractured cadaveric clavicle in the middle and divided into two treatment groups. The first treatment group was given plate fixation and two screws on each side of the fracture, the second treatment group with plate fixation and three screws. Each group was given a repetitive load tensile force of $200 \mathrm{~N}$, and the fracture shift was measured every ten times, 20 times, and 50 times. The statistical analysis showed a significant difference between plate fixation with two screws and three screws on the tensile force's repetition 20 times and 50 times. The lowest average displacement value after repetition of tensile forces is found in fixation with three screws. Biomechanically, the plate fixation system with three screws on each fracture side was more stable than the two screws in the middle clavicle fracture fixation.
\end{abstract}




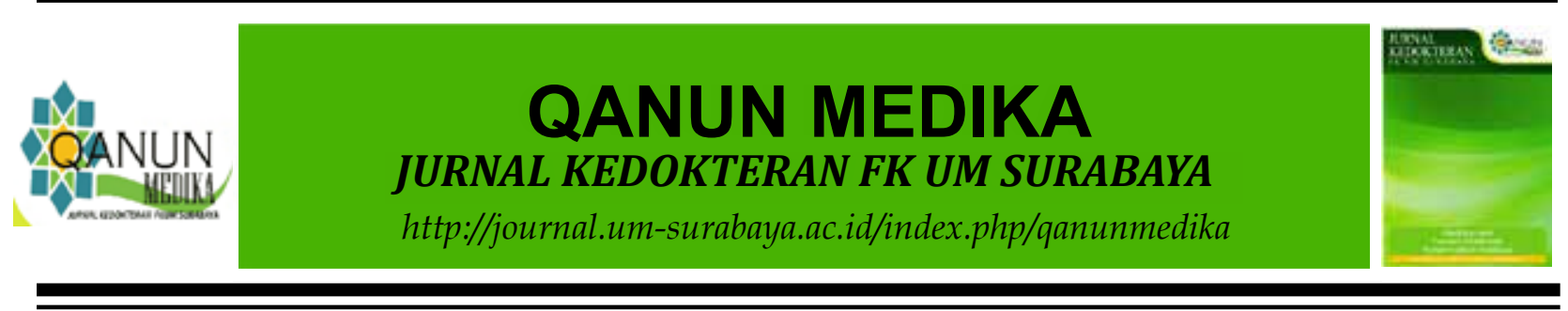

INTRODUCTION

A clavicle fracture is a common injury between $2.6 \%$ and $4 \%$ of adult fractures and approximately $35 \%$ of all shoulder injuries (C Michael Robinson, 1998). Fractures in the middle third of the clavicle are the most common fractures, with a percentage ranging from $69 \%$ to $82 \%$ of all clavicle fractures (Jeray, 2007; Postacchini et al., 2002). Clavicle fracture management can be performed operatively or non-operatively (Liu et al., 2013). However, nonoperative treatment outcomes are not as favorable as once thought, and the trend to surgically treat these fractures has grown (Hill et al., 1997). The optimal implant for clavicular fixation remains controversial (Kleweno et al., 2011; Narsaria et al., 2014). Plate fixation produces low implant failure rates and more rigid constructs than pins (Duan et al., 2011). One study comparing operative and nonoperative management has shown that plate fixation in middle-third clavicle fractures results in improved functional and lower rates of malunion and non-union (Laursen \& Døssing, 1999).

The standard surgical technique for plate fixation in middle-third clavicle fractures involves at least three bicortical screws in the medial and also lateral fragments of the fracture to hold the six cortices on each side of the fracture fragment; however, in some cases, two bicortical screws are used on each side of the fracture fragment. This has led to a debate about the cortex's minimum number held by a screw in each fracture segment (Hak et al., 2010). Several studies compared biomechanical tests between two locking screws and three non-locking screws on each side of the mid-clavicle fracture. However, this is the first study to examine the biomechanical comparison between two non-locking screws and three non-locking screws on each side of the mid-clavicle fracture. This can prove whether the stability of the plate is related to the number of non-locking screws.

\section{METHODS}

This research is experimental in vitro study with a randomized control post-test-only group design. This study had been reviewed and received an ethical exemption from the Health Research Ethics Committee, School of Medicine, Airlangga University (No.28 / EC / KEPK / FKUA / 2020). Only clavicles without signs of damage, fractures, or irregularities were included. This study used total sampling with a sample size are 12 cadaveric clavicles were collected from January to March 2020. The cadaveric clavicle was fractured in the middle with a simple (transverse) fracture configuration as samples that met the inclusion criteria, then divided randomly into two groups (each group consisting of six clavicle cadavers), namely the first treatment group (P1) was fixed with two screws on each side of the fracture, the second treatment group (P2) was fixed with three screws on each side of the fracture. The implants used in each group were nonlocking one-third tubular plate $3.5 \mathrm{~mm}$ with six holes (Ortho Fixor, Shagun Cares, India) and non-locking cortical screws. We designed our biomechanical study to represent this surgical technique because the plate was fixed to the clavicle's superior surface, providing a straighter plate fixation surface. For the P1 group, holding the plate in position on the bone, we drilled three parallel bicortical holes with a 2.5-mm-diameter drill. Screws were inserted between the bone and the plate to apply pullout forces between the plate and the bone and in line with the long axis of the screws. The screws were inserted into all holes (three screws on each side of the fractures) (Figure 1). Each screw was inserted to reach the far cortex. For the $\mathrm{P} 2$ group, the same technique and plate type were utilized except that we drilled two parallel bicortical holes with a 2.5 -mm-diameter drill 
and inserted two screws into the first and third hole positions on the plate (Figure 1).

Each group compared the displacement of the fracture fragments after fixation and repetitive tensile strength. The shift was measured by comparing the distance between the two points before and after being given a repetitive loadpull using a caliper (Figure 2). The load was given at $200 \mathrm{~N}$, then repeated ten times, 20 times, and 50 times. The load of $200 \mathrm{~N}$ represented the maximum force on the clavicle because the most significant force that affects the midshaft clavicle is dynamic muscle force. According to Dyrna research, the muscle that affects the most midshaft clavicle is the deltoid muscle, which is $200 \mathrm{~N}$ on approximately (Dyrna et al., 2018; Iannolo et al., 2010). This is why researchers used $200 \mathrm{~N}$ for the force tested.

The tools and materials used were the Shimadzu AG-10 TE autograft engine and calipers. The clavicle bone that was fixed with a plate and screw was placed on an autograft machine (Figure 3). Between the two sides of each clavicle, fragments were marked with a dot. Before testing the tensile force, the distance between the two marker points was first measured using a caliper. The pull force of the autograft machine was given a load of $200 \mathrm{~N}$ and was repeated continuously. The engine pull was paused on the ten times, 20 times, and 50 times repetitions, and measurements were taken at both marker points. This research was conducted at the Special Testing Laboratory of the Faculty of Civil Engineering, Sepuluh November Institute of Technology, and the Laboratory of the Anatomy Department, Faculty of Medicine, Airlangga University.

The collected data will be analyzed statistically using SPSS Version 22.0 (SPSS Inc., Chicago, IL, USA). In this study, data were obtained in the form of quantitative data. The normality test was carried out using the Shapiro-Wilk test; if an abnormal distribution was found for each variable, it would be continued with the non-parametric Mann-Whitney test. Statistical significance was defined as $p<0.05$.
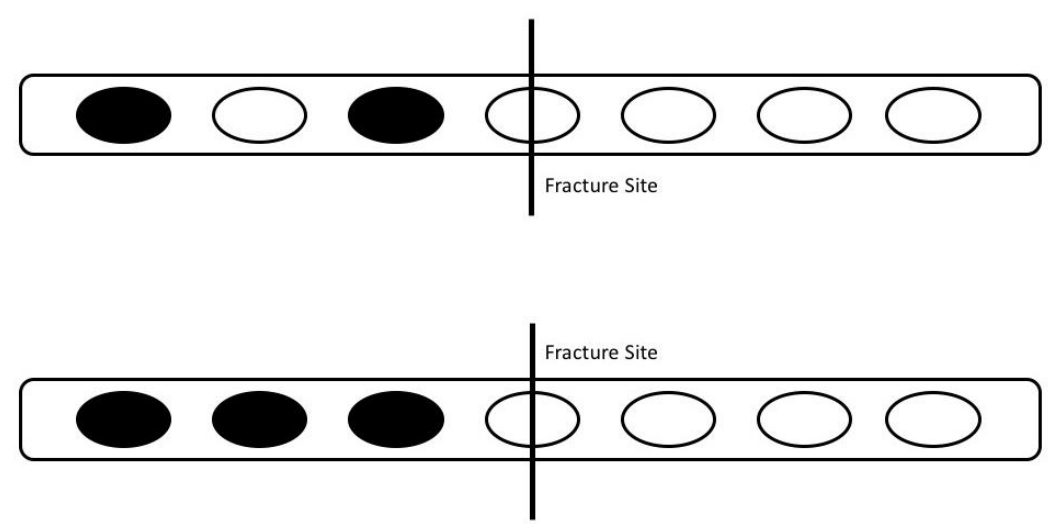

Figure 1. Location for plate application using two non-locking screws and three non-locking screws 


\section{QANUN MEDIKA Vol 6 | No 1 JANUARY 2022}
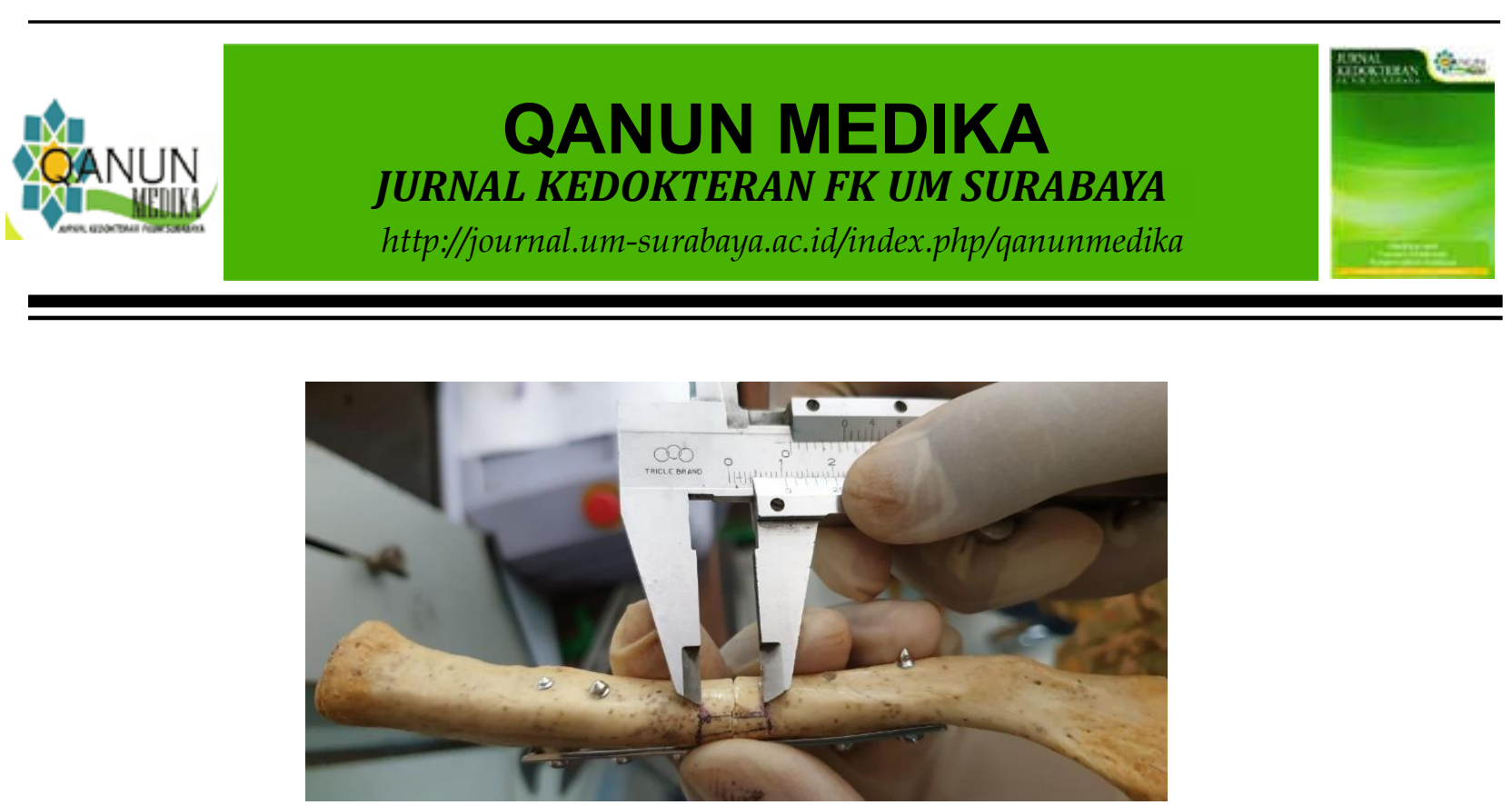

Figure 2. Measurement of the fracture line post tensile test

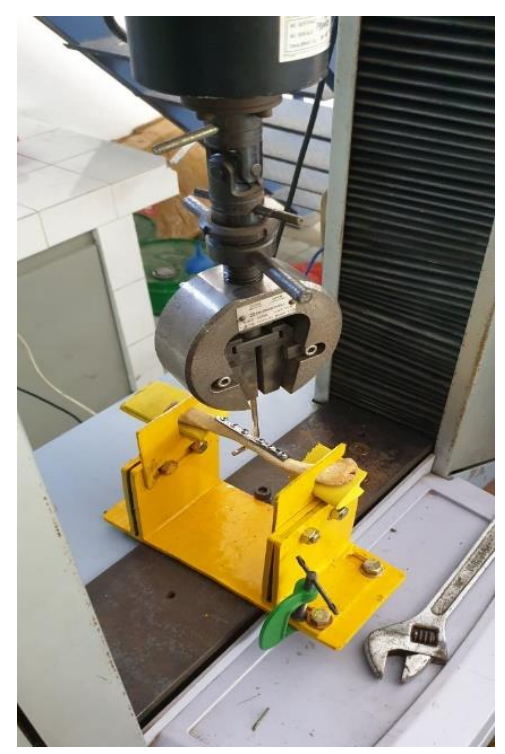

Figure 3. Clavicle Cadaver in Testing Equipment

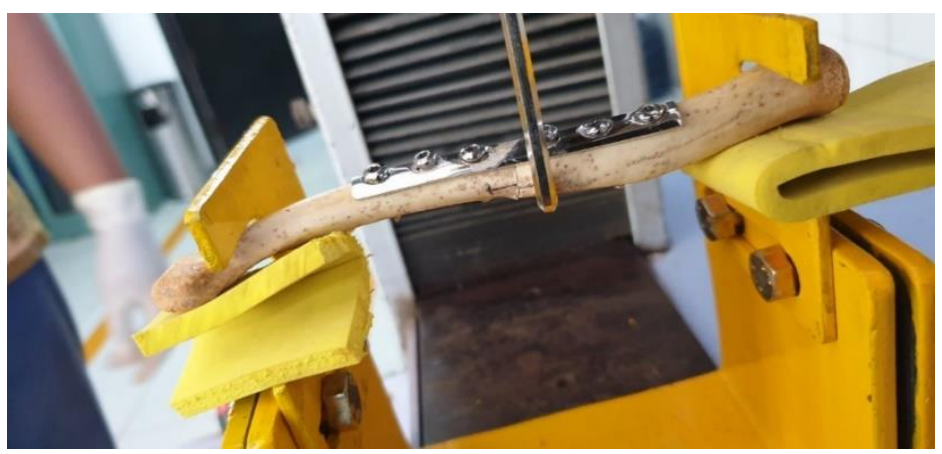

Figure 4. Example of the testing process of the clavicle cadaver with Repetitive Load Tensile Force Causing a Fracture Line Shift 


\section{QANUN MEDIKA}

\section{RESULTS}

In this study, biomechanical tests were carried out on 12 cadaveric clavicle samples that had met the inclusion criteria. The results found the displacement value of each sample's two marker points on repetitions often ten times, 20 times, and 50 times as shown in Table 1.
This study found that the average displacement value was lower in the fixation with three screws than two screws (Table 2). There was a significant difference between plate fixation with two screws and three screws at the repetition of the tensile force of 20 times $(p$ $=0.007)$ and 50 times $(p=0.003)$. Still, there was no significant difference in the repetition of tensile forces as much as ten times $(\mathrm{p}=$ 0.120 ), as listed in Table 2.

Table 1. The shift distance for each sample in the biomechanical test

\begin{tabular}{|c|c|c|c|c|c|}
\hline No. & Sample Name & Information & $\begin{array}{l}\text { Ten times } \\
(\mathrm{mm})\end{array}$ & $\begin{array}{l}20 \text { times } \\
(\mathrm{mm})\end{array}$ & $\begin{array}{c}50 \text { times } \\
(\mathrm{mm})\end{array}$ \\
\hline 1. & $1 \mathrm{~A}$ & Plate and two screws (1) & 10 & 25 & 38 \\
\hline 2. & 1B & Plate and two screws (2) & 10 & 20 & 23 \\
\hline 3. & $1 \mathrm{C}$ & Plate and two screws (3) & 8 & 15 & 20 \\
\hline 4. & $1 \mathrm{D}$ & Plate and two screws (4) & 10 & 15 & 25 \\
\hline 5. & $1 \mathrm{E}$ & Plate and two screws (5) & 10 & 15 & 20 \\
\hline 6. & $1 \mathrm{~F}$ & Plate and two screws (6) & 5 & 10 & 20 \\
\hline 7. & $2 \mathrm{~A}$ & Plate and three screws (1) & 0 & 5 & 10 \\
\hline 8. & $2 \mathrm{~B}$ & Plate and three screws (2) & 5 & 10 & 10 \\
\hline 9. & $2 \mathrm{C}$ & Plate and three screws (3) & 0 & 8 & 10 \\
\hline 10. & $2 \mathrm{D}$ & Plate and three screws (4) & 10 & 10 & 15 \\
\hline 11. & $2 \mathrm{E}$ & Plate and three screws (5) & 10 & 10 & 15 \\
\hline 12. & $2 \mathrm{~F}$ & Plate and three screws (6) & 5 & 10 & 15 \\
\hline
\end{tabular}




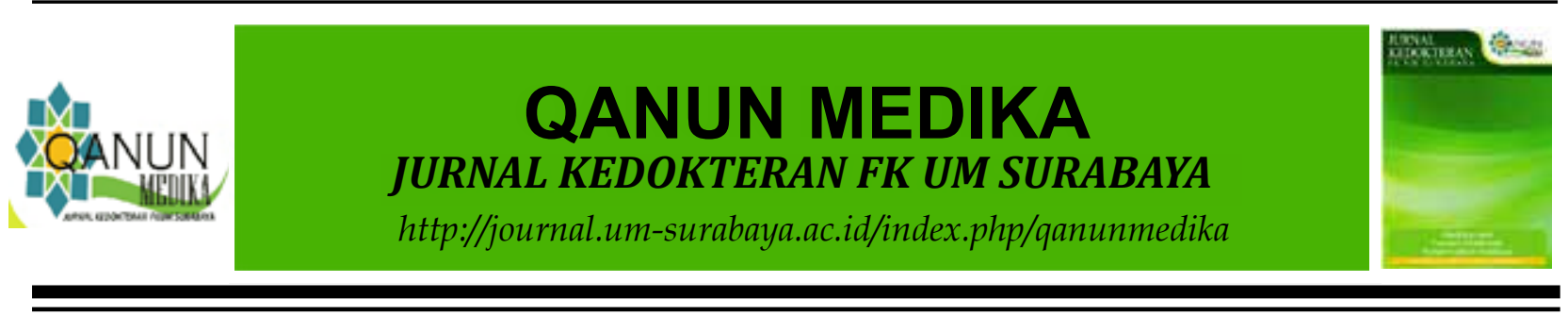

Table 2. The biomechanical tests analysis between fixation with two screws and three screws on the repetition of load tensile forces as much as ten times, 20 times, and 50 times

\begin{tabular}{lccc}
\hline \multicolumn{1}{c}{ Repetition } & 2 screws $(\mathbf{n}=\mathbf{6})$ & 3 screws $(\mathbf{n}=\mathbf{6})$ & P-value \\
\hline Ten times & $8.83 \pm 2.041$ & $5.00 \pm 4.472$ & 0.120 \\
20 times & $16.67 \pm 5.164$ & $8.83 \pm 2.041$ & $0.007^{*}$ \\
50 times & $24.33 \pm 7.005$ & $12.5 \pm 2.739$ & $0.003^{*}$ \\
\hline
\end{tabular}

Values are presented as Mean + SD (standard deviation).

Significant if $\mathrm{p}$ value $<0.05$

*significant value $(\mathrm{p}<0.05)$

\section{DISCUSSION}

Not surprisingly, the middle third is the most common site of clavicle fracture because it is the thinnest and narrowest part of the bone. It is the transitional area of the bone in curvature and lateral anatomy, making it a mechanically weaker area, and is the only area in the clavicle with no ligaments or muscle support. The indications for operative reparation of midshaft clavicle fractures expand; there is a clinical necessity to elucidate differences in biomechanical constancy among different operative procedures and implants used for fracture fixation to provide optimal stability. Compression plates and investigated the role of either superior or anterior-inferior plate location on fracture fixation biomechanics affect operative therapy (Celestre et al., 2008). The clavicle's biomechanics are six directions: tension-compression, torque, superiorinferior, and anterior-posterior (Iannolo et al., 2010).

Fixation stability is an essential concern for bone fracture treatment (Ye et al., 2015). Operative treatment has been recommended for displaced midshaft clavicle fracture (C M Robinson et al., 2013) because of the various problems that can occur with nonoperative treatment, including pain, instability, difficulty in daily care due to multiple trauma, and high nonunion rates in cases of severe displacement and initial shortening $>2 \mathrm{~cm}$ (Altamimi \& McKee, 2008; Smekal et al., 2009). One study stated that operative therapy with open reduction and plate fixation is a reliable method for diminishing the risk of non-union after displaced midshaft clavicular fracture (Society, 2007; Zlowodzki et al., 2005). Another study comparing operative and nonoperative management has shown that plate fixation in middle-third clavicle fractures results in improved functional and lower rates of malunion and non-union (Laursen \& Døssing, 1999). Until recently, the cortex's minimum number held by a screw in each fracture segment was still a matter of debate (Hak et al., 2010). However, according to Thyagarajan, the operative management of using plates in the middle of the third clavicular fracture requires at least three bicortical screws on each side of the fracture (Thyagarajan et al., 2009).

This study aims to compare plate fixation stability between two non-locking screws and three non-locking screws on each side of the midshaft clavicle fracture. This study shows that the plate fixation with three non-locking screws is more stable than two non-locking screws. A previous study compared stiffness, 
yield, and ultimate load between fixation with two screws locking compared with three nonlocking screws on each side of the fracture in the middle third clavicle fracture with cyclic load testing and in-line pullout testing found no meaningful difference (Grawe et al., 2012; Larsen et al., 2017). Another study showed that the two screws' stiffness was $20 \%$ lower than the three screws constructs on the locking plate (Bilmont et al., 2015).

This study still has several limitations. First, research still used a limited type of implants, whereas locking plate implants were widely used in clavicle fracture cases. Second, the number of samples was still small. We hope that there will be better studies with more extensive sampling and more varied use of implants in the future.

\section{CONCLUSION}

According to the biomechanical test results, the plate fixation system with three non-locking screws on each side of the fracture was more stable and significantly different from the two non-locking screws in the middle clavicle fracture fixation. Plate fixation with three screws on each side of the midshaft clavicle fracture is an alternative fixation with better stability than the fixation of two screws on each fracture side.

\section{REFERENCES}

Altamimi, S. A., \& McKee, M. D. (2008). Nonoperative treatment compared with plate fixation of displaced midshaft clavicular fractures: Surgical technique. JBJS, 90(Supplement_2_Part_1), 1-8.

Bilmont, A., Palierne, S., Verset, M., Swider, P., \& Autefage, A. (2015). Biomechanical comparison of two locking plate constructs under cyclic torsional loading in a fracture gap model. Veterinary and Comparative Orthopaedics and Traumatology, 28(5), 323-330.
Celestre, P., Roberston, C., Mahar, A., Oka, R., Meunier, M., \& Schwartz, A. (2008). Biomechanical evaluation of clavicle fracture plating techniques: does a locking plate provide improved stability? Journal of Orthopaedic Trauma, 22(4), 241-247.

Duan, X., Zhong, G., Cen, S., Huang, F., \& Xiang, Z. (2011). Plating versus intramedullary pin or conservative treatment for midshaft fracture of clavicle: a meta-analysis of randomized controlled trials. Journal of Shoulder and Elbow Surgery, 20(6), 1008-1015.

Dyrna, F., Kumar, N. S., Obopilwe, E., Scheiderer, B., Comer, B., Nowak, M., Romeo, A.A., Mazzocca, A. D., \& Beitzel, K. (2018). Relationship between deltoid and rotator cuff muscles during dynamic shoulder abduction: a biomechanical study of rotator cuff tear progression. The American Journal of Sports Medicine, 46(8), 1919-1926.

Grawe, B., Le, T., Williamson, S., Archdeacon, A., \& Zardiackas, L. (2012). Fracture fixation with two locking screws versus three non-locking screws: A biomechanical comparison in a normal and an osteoporotic bone model. Bone \& Joint Research, 1(6), 118-124.

Hak, D. J., Althausen, P., \& Hazelwood, S. J. (2010). Locked plate fixation of osteoporotic humeral shaft fractures: are two locking screws per segment enough? Journal of Orthopaedic Trauma, 24(4), 207-211.

Hill, J. M., McGuire, M. H., \& Crosby, L. A. (1997). Closed treatment of displaced middle-third fractures of the clavicle gives poor results. The Journal of Bone and Joint Surgery. British Volume, 79(4), 537-538.

Iannolo, M., Werner, F. W., Sutton, L. G., 


\section{QANUN MEDIKA}

JURNAL KEDOKTERAN FK UM SURABAYA

http://journal.um-surabaya.ac.id/index.php/qanunmedika

Serell, S. M., \& VanValkenburg, S. M. (2010). Forces across the middle of the intact clavicle during shoulder motion. Journal of Shoulder and Elbow Surgery, 19(7), 1013-1017.

Jeray, K. J. (2007). Acute midshaft clavicular fracture. JAAOS-Journal of the American Academy of Orthopaedic Surgeons, 15(4), 239-248.

Kleweno, C. P., Jawa, A., Wells, J. H., O’Brien, T. G., Higgins, L. D., Harris, M. B., \& Warner, J. J. P. (2011). Midshaft clavicular fractures: comparison of intramedullary pin and plate fixation. Journal of Shoulder and Elbow Surgery, 20(7), 1114-1117.

Larsen, C. G., Sleasman, B., \& Chudik, S. C. (2017). A Biomechanical and Clinical Comparison of Midshaft Clavicle Plate Fixation: Are 2 Screws as Good as 3 on Each Side of the Fracture? Orthopaedic Journal of Sports Medicine, 5(9), 2325967117725293.

Laursen, M. B., \& Døssing, K. V. (1999). Clavicular nonunions treated with compression plate fixation and cancellous bone grafting: the functional outcome. Journal of Shoulder and Elbow Surgery, 8(5), 410-413.

Liu, G., Tong, S., Ou, S., Zhou, L., Fei, J., Nan, G., \& Gu, J. (2013). Operative versus nonoperative treatment for clavicle fracture: a meta-analysis. International Orthopaedics, 37(8), 1495-1500.

Narsaria, N., Singh, A. K., Arun, G. R., \& Seth, R. R. S. (2014). Surgical fixation of displaced midshaft clavicle fractures: elastic intramedullary nailing versus precontoured plating. Journal of Orthopaedics and Traumatology, 15(3), 165-171.

Postacchini, F., Gumina, S., De Santis, P., \& Albo, F. (2002). Epidemiology of clavicle fractures. Journal of Shoulder and Elbow Surgery, 11(5), 452-456.

Robinson, C M, Goudie, E. B., Murray, I. R., Jenkins, P. J., Ahktar, M. A., Reed, E. O., Foster, C. J., Clark, K., Brooksbank, A. J., \& Arthur, A. (2013). Open reduction and plate fixation versus nonoperative treatment for displaced midshaft clavicular fractures: a multicenter, randomized, controlled trial. JBJS, 95(17), 1576-1584.

Robinson, C Michael. (1998). Fractures of the clavicle in the adult: epidemiology and classification. The Journal of Bone and Joint Surgery. British Volume, 80(3), 476484.

Smekal, V., Oberladstaetter, J., Struve, P., \& Krappinger, D. (2009). Shaft fractures of the clavicle: current concepts. Archives of Orthopaedic and Trauma Surgery, 129(6), 807-815.

Society, C. O. T. (2007). Nonoperative treatment compared with plate fixation of displaced midshaft clavicular fractures. A multicenter, randomized clinical trial. The Journal of Bone and Joint Surgery. American Volume, 89(1), 1-10.

Thyagarajan, D. S., Day, M., Dent, C., Williams, R., \& Evans, R. (2009). Treatment of midshaft clavicle fractures: a comparative study. International Journal of Shoulder Surgery, 3(2), 23.

Ye, Y., Hao, J., Mauffrey, C., Hammerberg, E. M., Stahel, P. F., \& Hak, D. J. (2015). Optimizing stability in femoral neck fracture fixation. Orthopedics, 38(10), 625-630.

Zlowodzki, M., Zelle, B. A., Cole, P. A., Jeray, K., \& McKee, M. D. (2005). Treatment of acute midshaft clavicle fractures: systematic review of 2144 fractures: on behalf of the Evidence-Based Orthopaedic Trauma Working Group. Journal of Orthopaedic Trauma, 19(7), 504-507. 